\title{
APLIKASI PEMBELAJARAN BAHASA INGGRIS DISERTAI KAMUS
}

\author{
Reski Annisaa $^{1}$, Rahmat Hidayatullah ${ }^{2}$ \\ 1,2 Sekolah Tinggi Manajemen Informatka Komputer (STMIK) Dumai \\ Jl. Karya Utama Bukit Batrem II Dumai - Riau \\ Email : annisaareski@yahoo.com
}

\begin{abstract}
ABSTRAK
Mempelajari 16 Tenses bahasa Inggris merupakan salah satu kegiatan pembelajaran bagi semua kalangan masyarakat. Saat ini penyampaian pembelajaran bahasa Inggris bagi pemula masih bersifat konvensional melalui media buku tanpa adanya media penyampaian yang menarik dan kurang interaktif. Sehubungan dengan hal tersebut, penulis membuat aplikasi pembelajaran bahasa Inggris disertai kamus dengan menggunakan metode aplikasi yang berbasis web yang bersifat menarik.Aplikasi pembelajaran ini dibuat karena masih banyak orang-orang yang kurang mengerti tentang pemahaman pembelajaran bahasa Inggris pemula, dimana ketika seseorang akan melakukan suatu kegiatan .Aplikasi pembelajaran bahasa Inggris disertai kamus, akan menampilkan materi pembelajaran, soal pembelajaran berupa soal pilihan ganda, dan kamus. Setelah user menyelesaikan soal-soal yang diberikan, user akan mendapatkan nilai yang sesuai dengan hasil penyelesaian soal-soal tersebut. Penelitian ini menghasilkan suatu aplikasi terutama yang dapat membuat masyarakat mempelajari bahasa Inggris pemula melalui user interface yang menarik, interaktif dan mudah digunakan dengan disertai soal latihan yang dibatasi oleh waktu pengerjaannya dan kamus. Aplikasi ini dibangun dengan menggunakan bahasa pemprograman PHP kemudian diintegrasikan menjadi sebuah aplikasi yang berbasis web, Aplikasi ini dijalankan pada sistem operasi komputer, mau pun smartphone.
\end{abstract}

Kata Kunci : Aplikasi, Bahasa Inggris, Kamus, PHP

\section{PENDAHULUAN}

Pembelajaran bahasa Inggris ini akan membantu masyarakat umum untuk mengetahui pembelajaran bahasa Inggris yang benar, yang mengenalkan 16 tenses dan kamus serta test soal bagi pemula, agar masyarakat lebih mengetahui pembelajaran bahasa Inggris yang lebih efisien. Sulitannya mendapatkan media pembelajaran bahasa Inggris yang efisien, membuat kurangnya tinggkat minat banyak orang terhadap pembelajaran bahasa Inggris di luar kegiatan ajarmengajar, dengan cara membaca buku dan kamus, membuat semua orang harus menggeluarkan biaya yang besar untuk membeli banyak buku, selain itu juga buku kurang praktis untuk dibawa kemanamana. Sehingga dibutuhkan suatu aplikasi pembelajaran bahasa inggris disertai kamus dengan menggunakan program PHP.

Bahasa Inggris adalah bahasajumerik yang pertama kalidituturkan di Inggris padaAbad pertengahan awal dan saat ini merupakan bahasa yang paling umum digunakan di seluruh dunia. Bahasa Inggris dituturkan sebagai bahasa pertama oleh mayoritas penduduk di berbagai negara, termasuk Britania Raya, Irlandia, Amerika Serikat, Kanada, Australia,Selandia Baru dan sejumlah negara-negara Karibia, serta menjadi bahasa resmi di hampir 60 negara berdaulat. Bahasa Inggris adalah bahasa ibu krtiga yang paling banyak dituturkan di seluruh dunia,

Kamus adalah sejenis buku rujukan yang menerangkan makna kata-kata. kamus berfungsi untuk membantu seseorang mengenal perkataan baru. Selain menerangkan maksud kata, kamus juuga mungkin mempunyai pedoman sebutan, asal usul

(etimologi) sesuatu oerkataan dan juga contoh penggunaan bagi sesuatu perkataan, untuk memperjelas kadang kala terdapat juga ilustrasi di dalam kamus.

\section{METODE PENELITIAN}

Kerangka penelitian yang di gunakan dalam penelitian ini adalah sebagai berikut : 
INFORM T I K A

Jurnal Informatika, Manajemen dan Komputer, Vol. 9 No. 1, Mei 2017

eISSN : 2580-3042

pISSN : 1979-0694

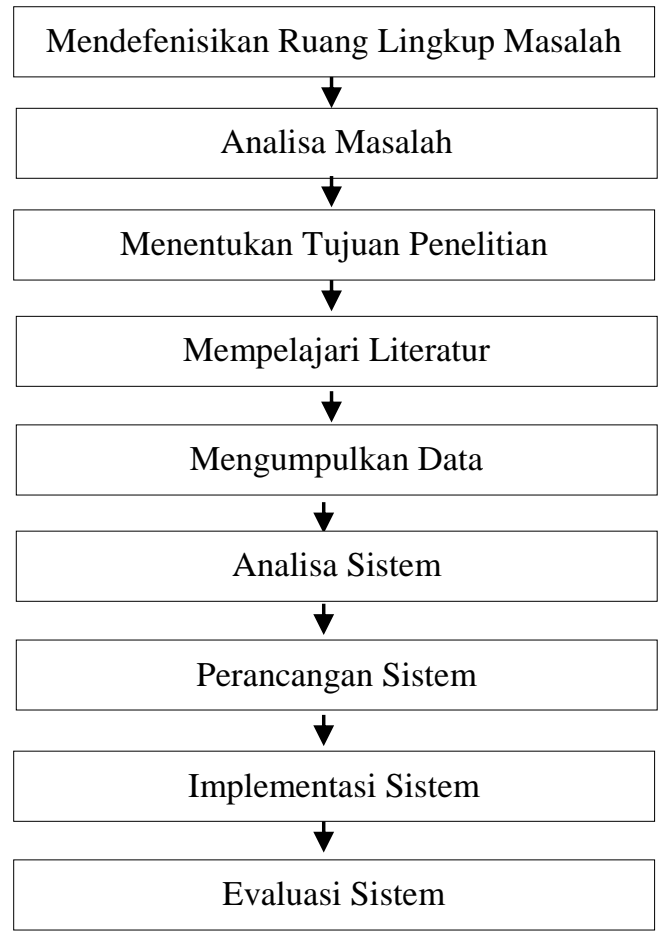

Gambar .1 Kerangka Penelitian

3. Analisis dan Perancangan Sistem 3.1 ASI Lama

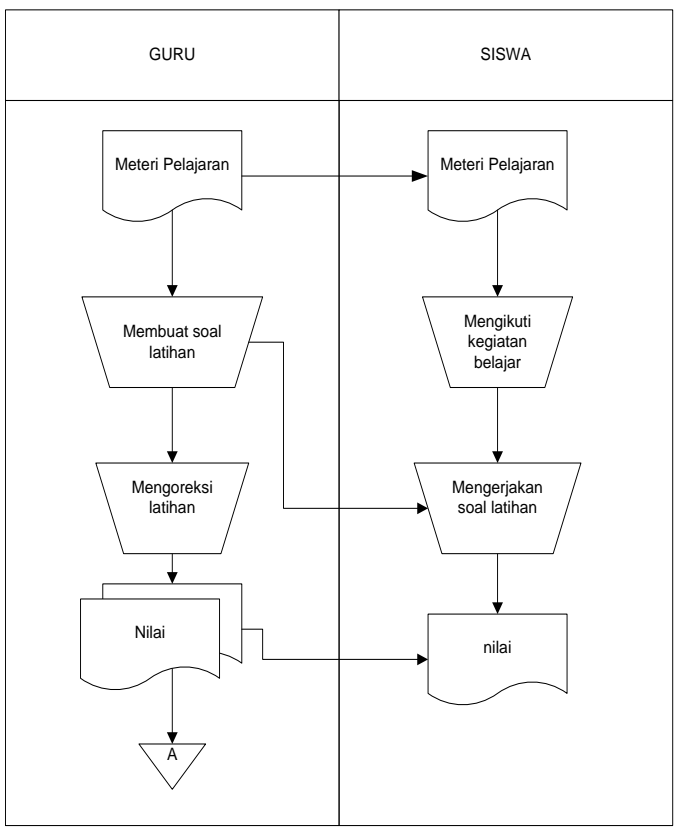

Gambar 2. Asi Lama

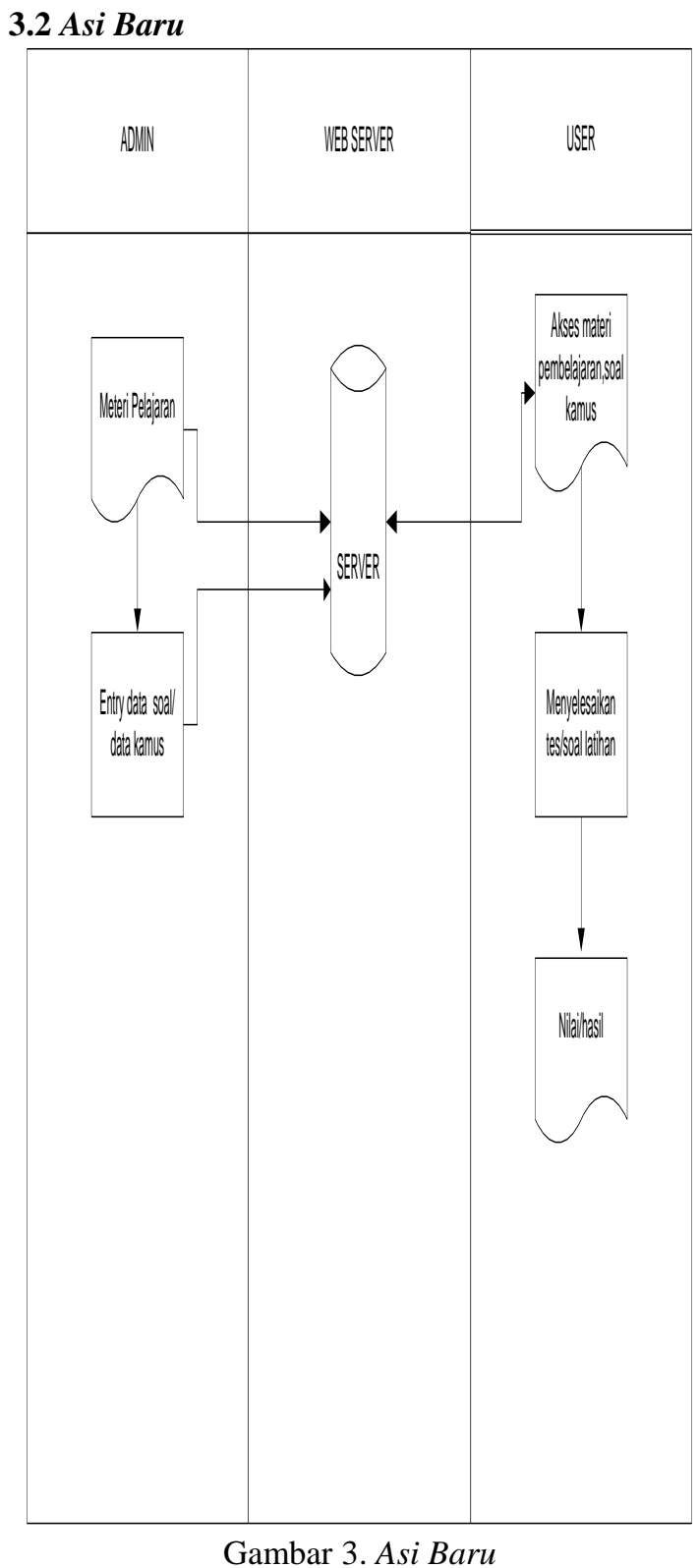

\subsection{Contex Diagram}

Context diagram adalah gambaran sistem secara logikal, gambaran ini tidak tergantung pada perangkat keras, perangkat lunak, atau organisasi File. Suatu context diagram selalu mengandung satu proses saja (diberi nomor proses 0), proses ini mewakili proses dari keseluruhan sistem. Contextdiagram menggambarkanhubunganinput / output antara sistem dengan dunia luarnya. 
IN F O RM A IK

Jurnal Informatika, Manajemen dan Komputer, Vol. 9 No. 1, Mei 2017

eISSN : 2580-3042

pISSN : 1979-0694

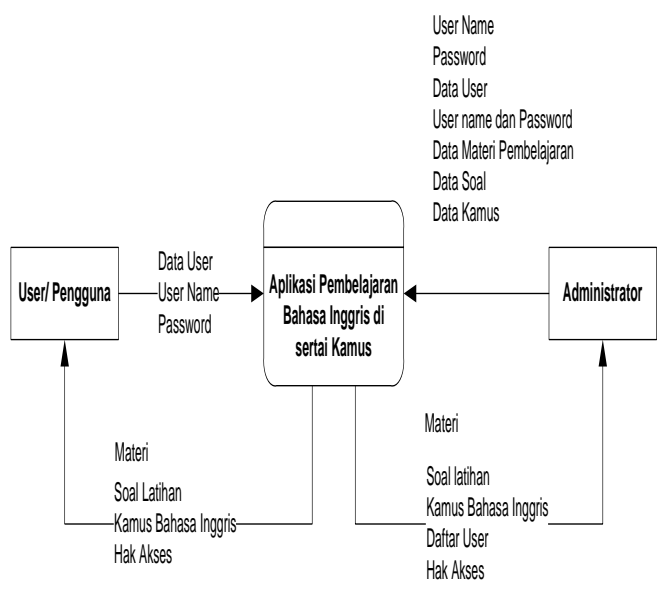

Gambar 4. Contex Diagram

\subsection{Disain Input Materi}

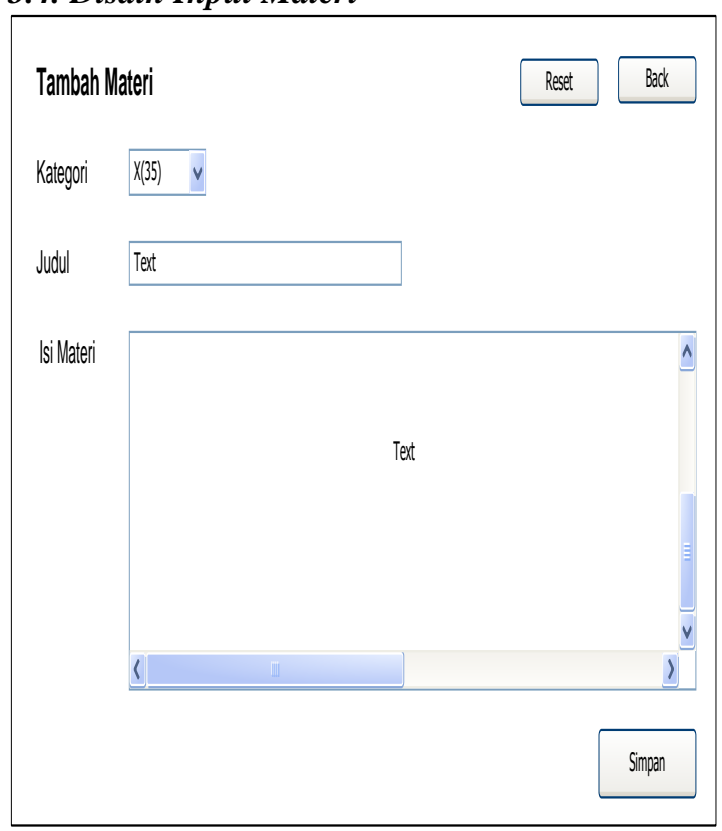

Gambar 5. Disain Input Materi

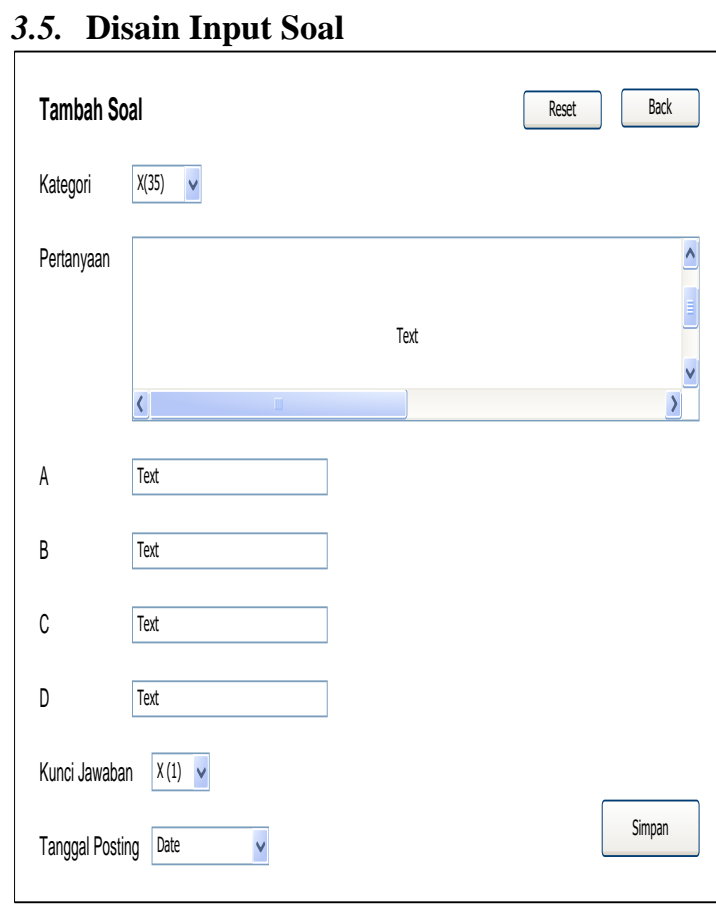

Gambar 6. Disain Input Soal

\subsection{Disain Input Timer}

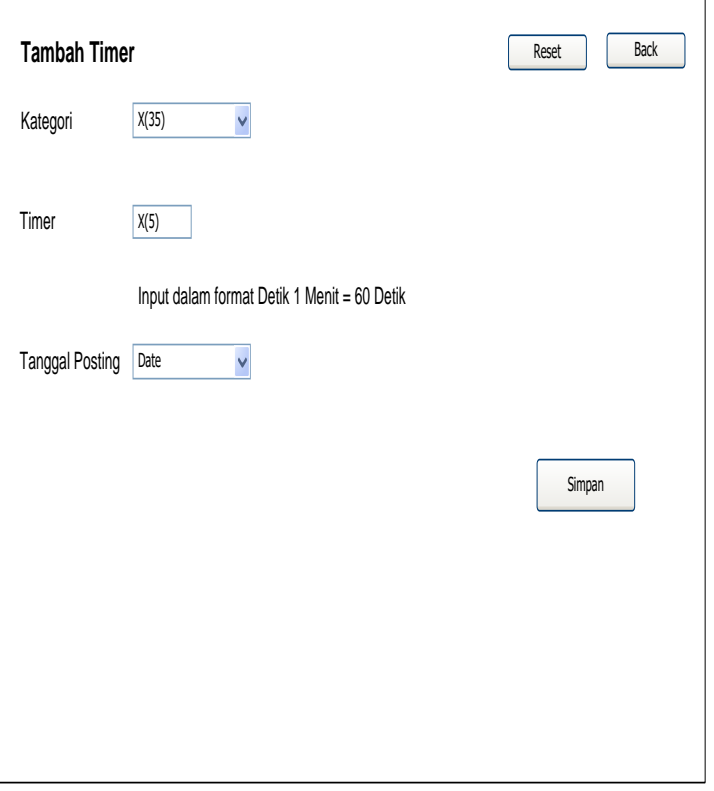

Gambar 7. Disain Input Timer 
IN F ORM T IKA

Jurnal Informatika, Manajemen dan Komputer, Vol. 9 No. 1, Mei 2017

eISSN : 2580-3042

pISSN : 1979-0694

\subsection{Disain Input Kategori}

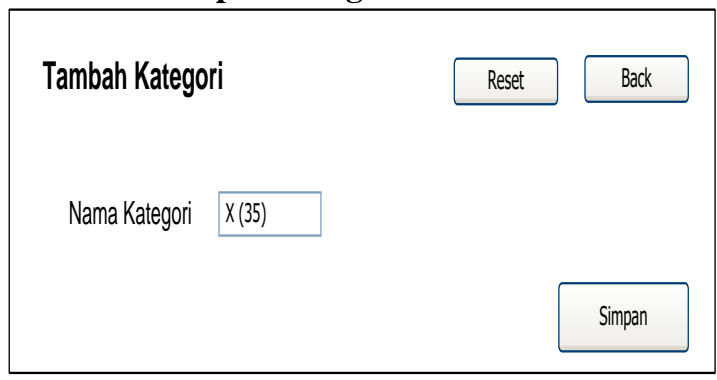

Gambar 8. Disain Input Kategori

\subsection{Disain Input Kamus}

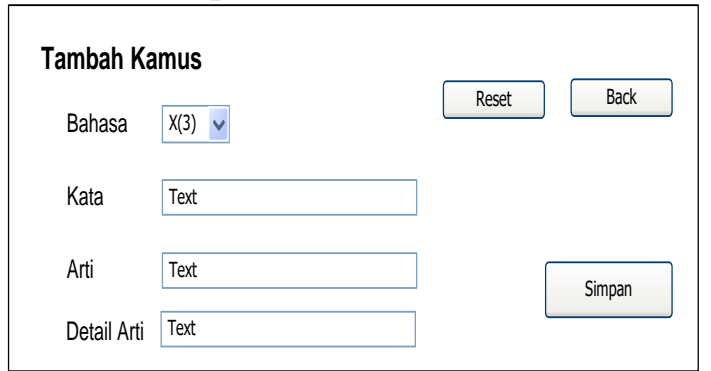

Gambar 9. Disain Input Kategori

\subsection{Flowchart Tambah Materi}

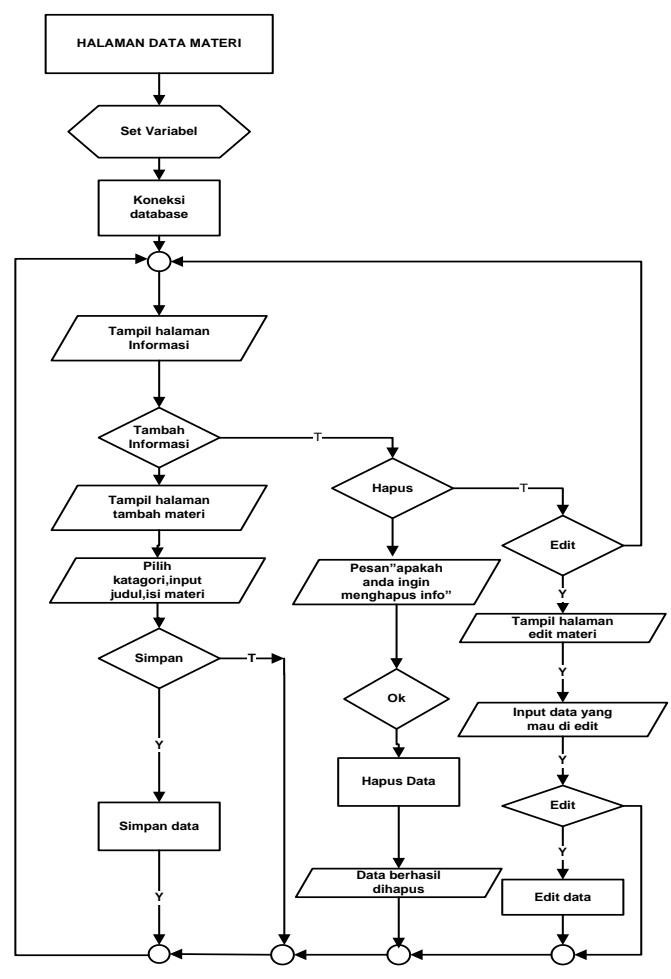

\subsection{Flowchart Tambah Soal}

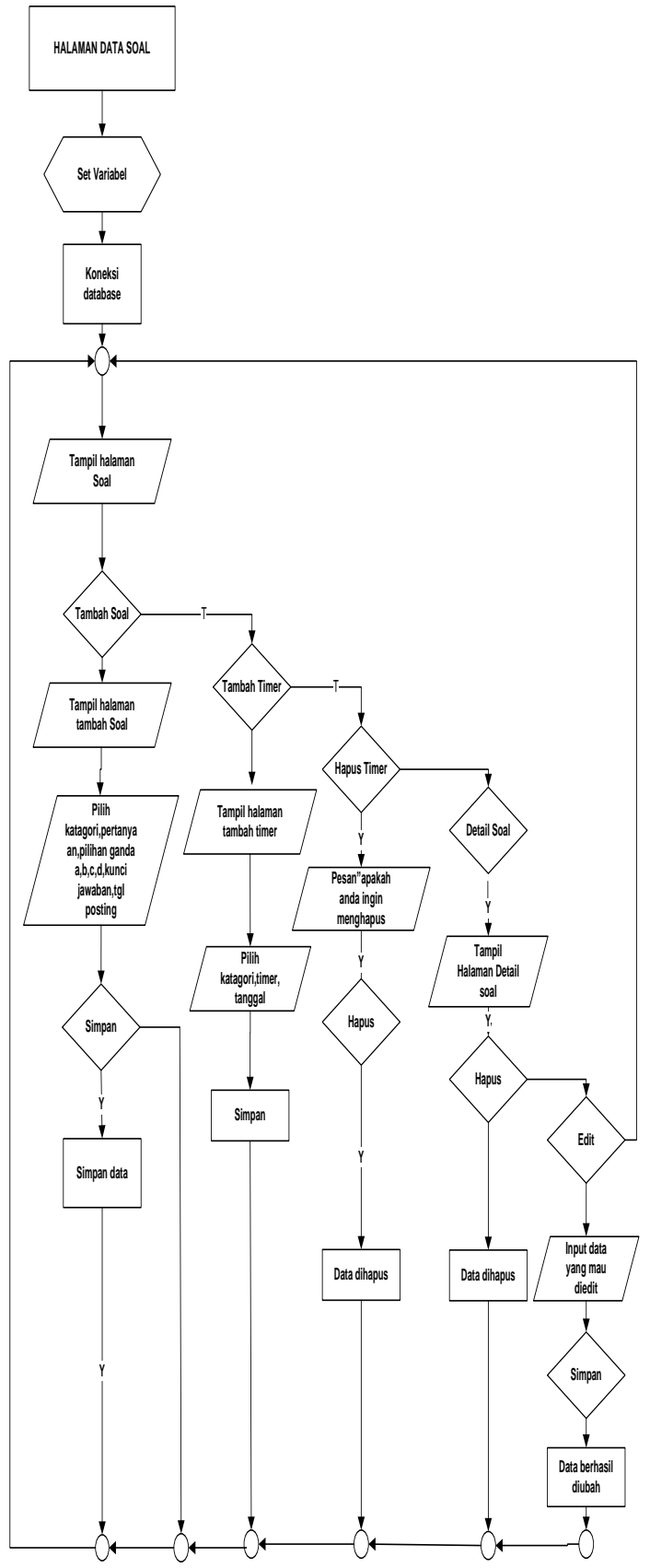

Gambar 11. Flowchart Tambah Soal

Gambar 10. Flowchart Tambah Materi 
I N F O R M A I K

Jurnal Informatika, Manajemen dan Komputer, Vol. 9 No. 1, Mei 2017

eISSN : 2580-3042

pISSN : 1979-0694

\subsection{Flowchart Tambah Kamus}

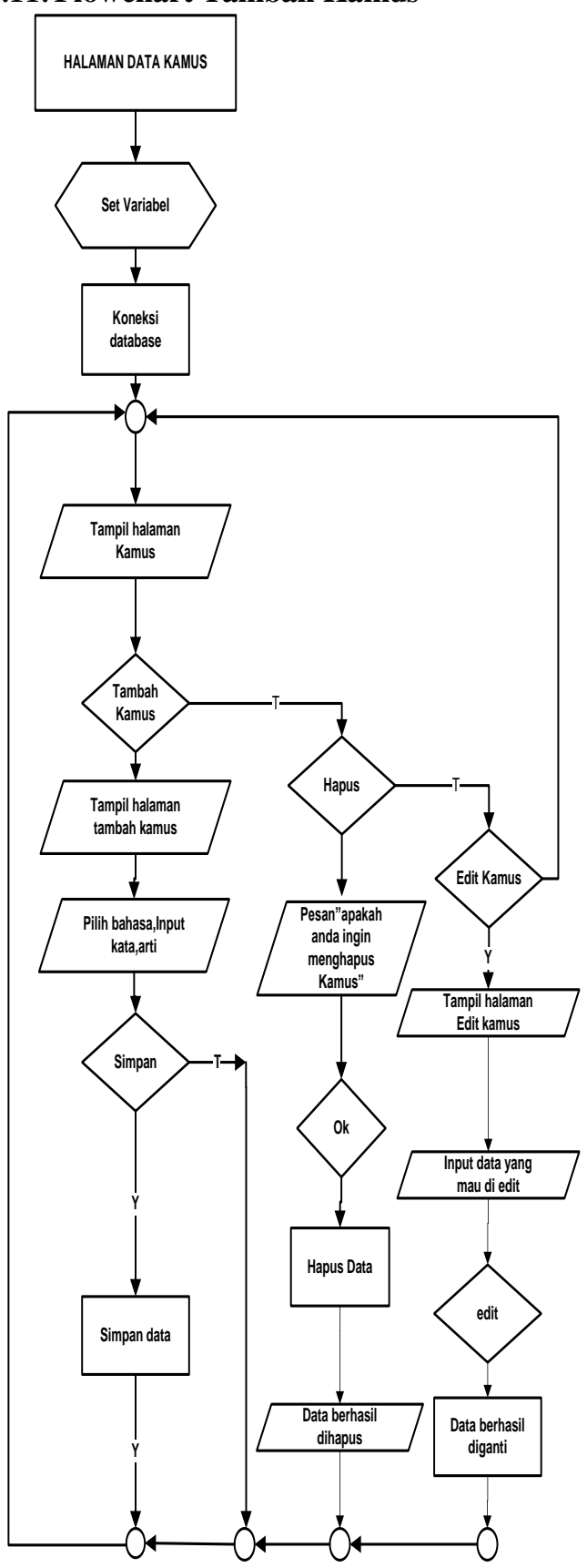

Gambar 12. Flowchart Tambah Kamus

\subsection{Manual Sistem}

\section{Tampilan Utama Pengguna}

Tampil halaman Utama Pengguna pada gambar ini menampilkan menu login untuk pengguna yang sudah register, dan menu register untuk pengguna yang belum mendaftar.

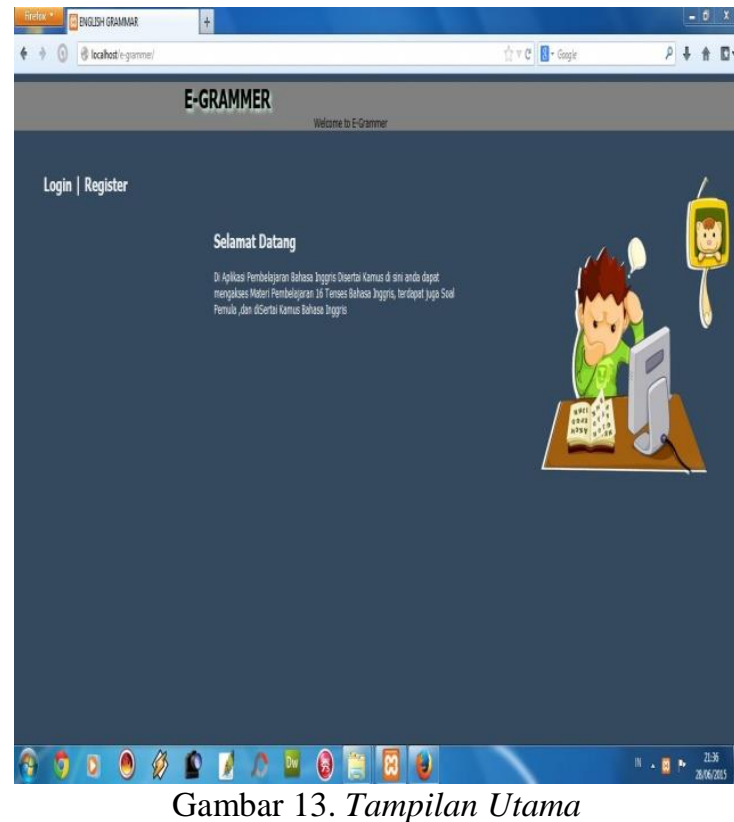

\section{Tampilan Register Pengguna}

Pada saat mulai aplikasi ini, sistem menampilkan form registrasi seperti pada gambar registeri, pengguna bisa login pada gambar login untuk masuk ke aplikasi pembelajaran bahasa Inggris di sertai kamus.

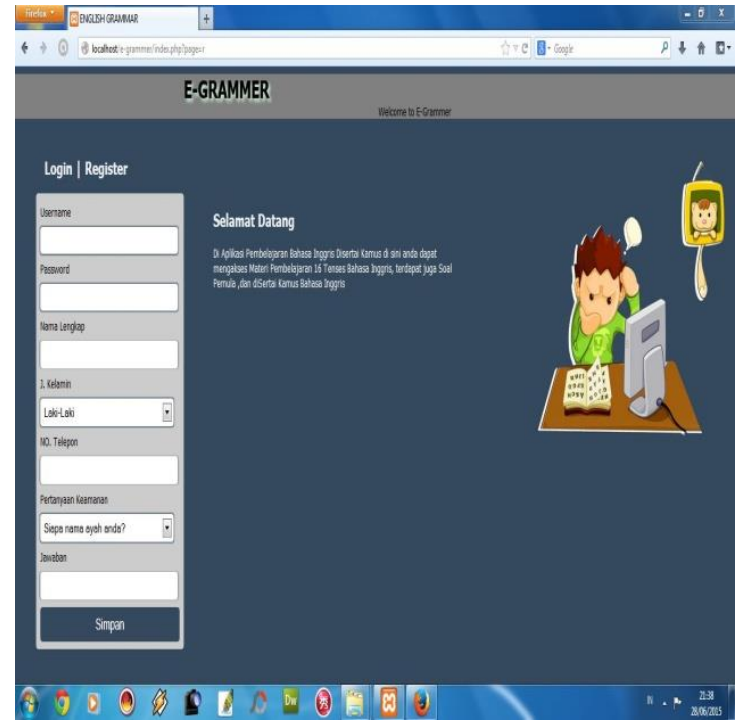

Gambar 14. Tampilan Register Pengguna

\section{Tampilan Login Pengguna}

Pada gambar ini tampil halaman login pengguna, jika ingin login langsung masukan username dan password user, agar bisa masuk kesistem. 
IN F ORM A I I A

Jurnal Informatika, Manajemen dan Komputer, Vol. 9 No. 1, Mei 2017

eISSN : 2580-3042

pISSN : 1979-0694

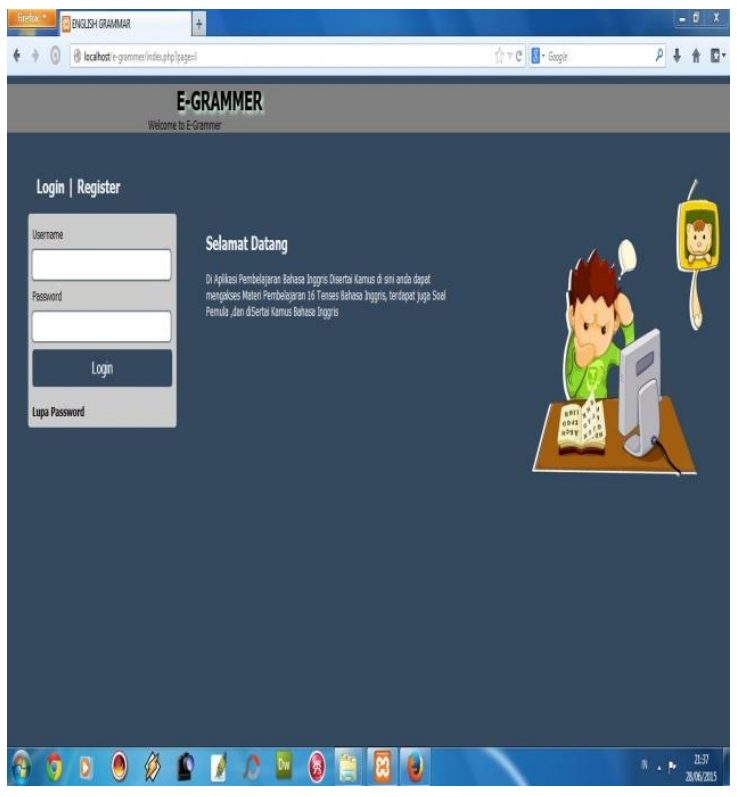

Gambar 15 Tampilan Login Pengguna

\section{Tampilan Lupa Password Pengguna}

Pada gambar ini tampil halaman lupa password user, user harus menginput No.hp dan username yang pernah di registrasi terdahulu, jika sudah lalu lanjut.
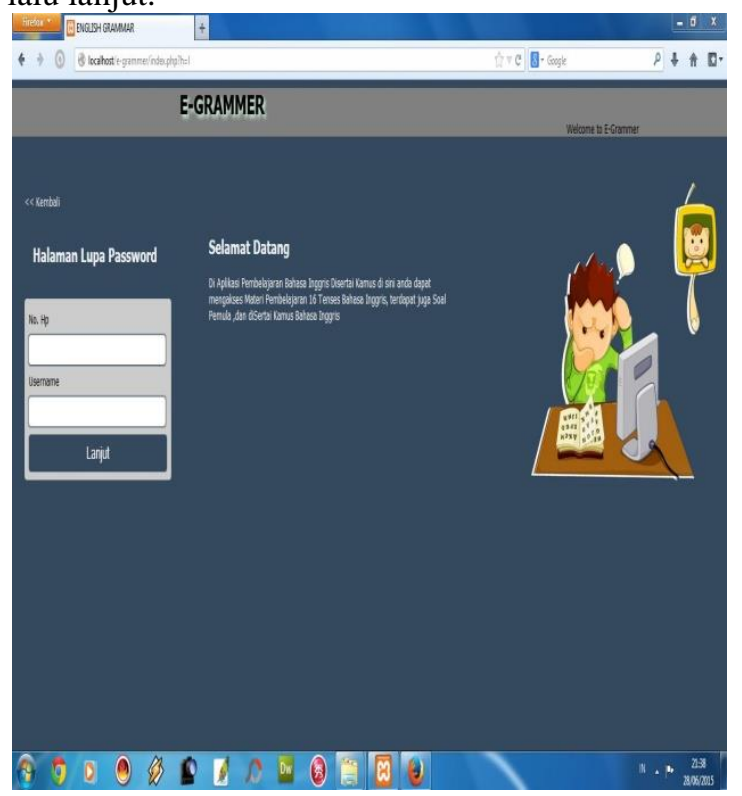

Gambar 16 Tampilan Lupa Password

Pengguna

\section{Tampilan Materi Pengguna}

Pada gambar ini form menu materi pengguna ini, sistem menampilkan form materi untuk menampilkan 16 (enam belas) materi tenses, Adapun beberapa materinya seperti simple present tense, present countinious tense, present perfect tense, present perfect countinous tense, simple past tense, dll, form pembelajaran yang menampilkan soal latihan, dan form kamus yang menampilkan kamus.

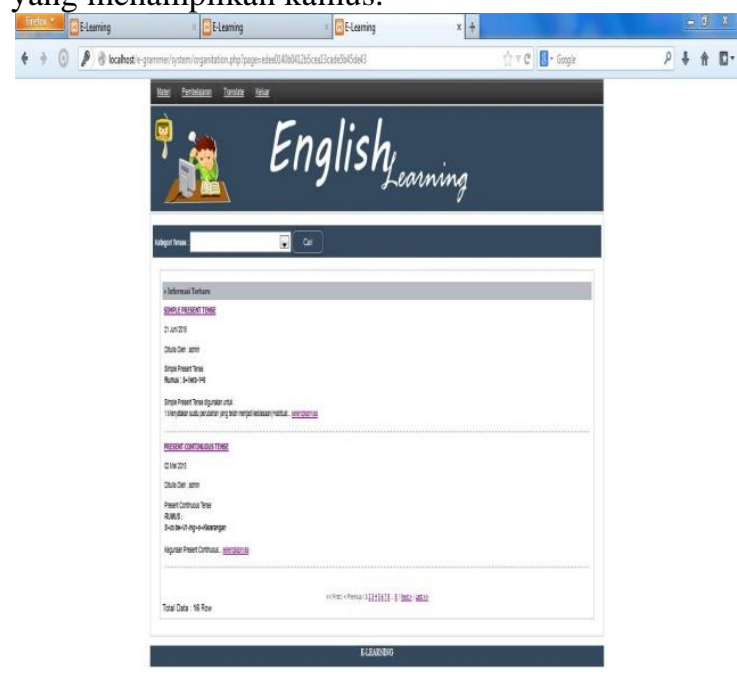

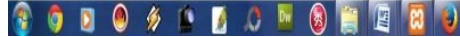

Gambar 16 Tampilan Materi Pengguna

\section{Tampilan Soal Pengguna}

Pada gambar ini form pembelajaran ini sistem menyediakan soal-soal dari semua materi yang terdapat pada menu materi. Soal-soal Tenses tersebut berbentuk pilihan ganda dan dengan waktu yang ditentukan..

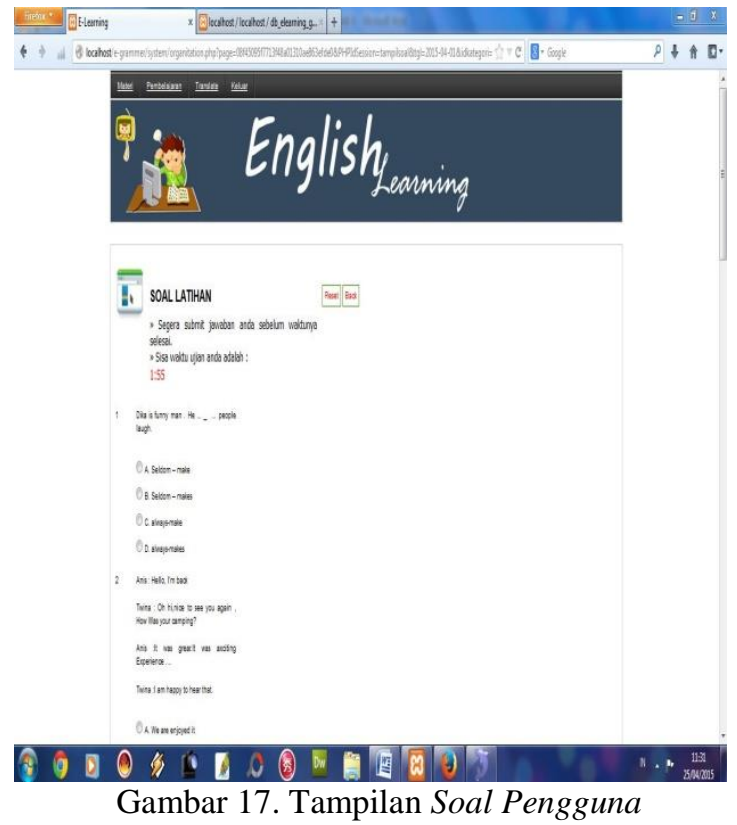

4.7 Tampilan Skor 
IN F O RM A I I A

Jurnal Informatika, Manajemen dan Komputer, Vol. 9 No. 1, Mei 2017

eISSN : 2580-3042

pISSN : 1979-0694

Form Skor pada gambar ini akan menampilkan skor dari hasil soal yang dikerjakan oleh pengguna.

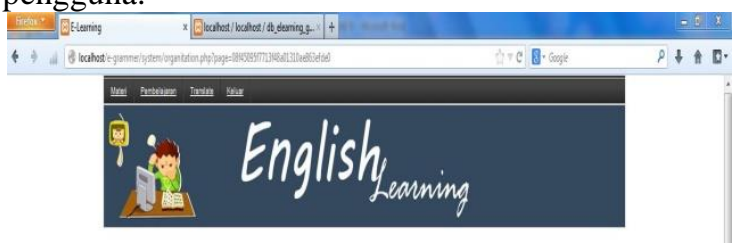

\subsection{Kesimpulan}

Aplikasi Pembelajaran bahasa Inggris disertai Kamus yang merupakan aplikasi yang menampilkan informasi tentang materi pembelajaran bahasa Inggris pemula Present Tense. Pengujian aplikasi ini telah dilakukan dan dapat dijalankan sesuai dengan perancangan yang telah dibuat. Program diimplementasikan dengan menggunakan bahasa pemograman PHP berbasis web pada komputer dan juga bisa diakses melalui smartphone.

Dari hasil peneletian yang penulis lakukan maka didapat kesimpulan dari analisa maupun hasil dari penulisan skripsi ini, diantaranya sebagai berikut :

1. Aplikasi ini dapat digunakan sebagai media pembelajaran bagi kalangan umum yang bisa menggunakan komputer, smartphone, tentang pembelajaran bahasa Inggris yang benar, yang mengenalkan 16 tenses dan kamus serta test soal bagi pemula.

2. Dengan dibangunnya program aplikasi pembelajaran bahasa Inggris diseretai kamus ini dapat membantu untuk melakukan sesuatu kegiatan kapanpun dan dimanapun ditengah kesibukan mereka dan aplikasi yang dibangunpun mudah untuk digunakan.

\section{Tampilan Kamus}

Pada gambar Form kamus ini, pengguna dapat mencari kosa kata yang ingin diterjemahkan dari bahasa Indonesia ke bahasa Inggris ataupun dari bahasa Inggris ke bahasa Indonesia seperti yang terdapat dalam kamus yang ada. Jika pengguna memilih tombol Indonesia - Inggris maka akan tampil halaman kamus pada dan jika pengguna memilih tombol Inggris - Indonesia maka akan tampil halaman kamus pada gambar.
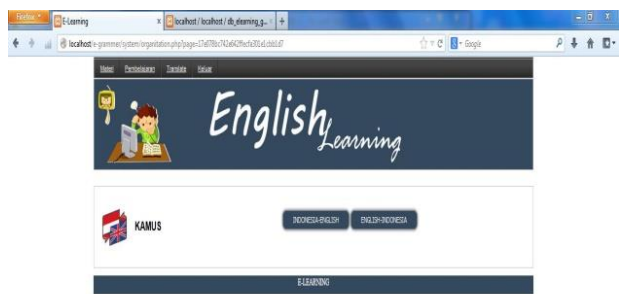

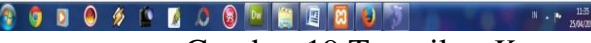 \\ Gambar 19 Tampilan Kamus}

\section{SIMPULAN}

3. Serta dilengkapi juga dengan evaluasi soal dalam bentuk soal pilihan ganda untuk mengukur seberapa besar nilai pembelajaran dari materi bahasa Inggris Present Tense.

\section{REFERENSI}

Agus Saputra dan lain-lain.(2013). Menyelesaikan Website 12 Juta Secara Profesional. Kompas Gramedia. Jakarta.

Arif, M. Rudyanto. (2011). Pemograman Web Dinamis Menggunakan PHP \& MySQL. ANDI. Yogyakarta.

Betha Sidik. (2009). Pemograman web dengan HTML, Informatika Bandung. Bandung.

Bunafit Nugroho. (2013). Dasar pemograman web Php-MySQL dengan dreamweaver. Yogyakarta.

Edhy Sutanta. (2011). Basis Data Dalam Tujuan Konseptual. ANDI. Yogyakarta.

Hanif Al Fatta. (2007). Analisis Dan Perancangan Sistem Informasi. ANDI. Yogyakarta.

Indrajani. (2011). Perancangan Basis Data Dalam All In1. Gramedia. Jakarta.

Simarmata Janner. (2007). Perancangan Basis Data. ANDI. Yogyakarta.

Kusrini. (2007). Strategi Perancang dan Pengelolahan Basis Data. ANDI. Yogyakarta. 
INFORM T IKA

Jurnal Informatika, Manajemen dan Komputer, Vol. 9 No. 1, Mei 2017

eISSN : 2580-3042

pISSN : 1979-0694

Lukmanul Hakim. (2013). Poyek website super wow! Dengan PHP \& jQuery. Loko Media, Yogyakarta.

Madcom. (2011). Aplikasi Web Database dengan Dreamweaver dan PHP-MySQL. ANDI. Yogyakarta

Rosa A.S.M. Shalahuddin. (2013). Rekayasa Perangkat Lunak Terstruktur dan Beriorintasi Objek. Informatika Bandung.

Bandung. 